\title{
Alternative Benchmarks for Evaluating REIT Mutual Fund Performance*
}

\author{
Jay C. Hartzell, ${ }^{\dagger}$ Tobias Mühlhofer, and Sheridan Titman \\ McCombs School of Business \\ The University of Texas at Austin
}

March 15, 2007

${ }^{*}$ We would like to thank Crocker Liu and Joe Pagliari for their helpful comments, and Shirley Birman and Alan Crane for research assistance. We also gratefully acknowledge the financial support of the Real Estate Research Institute. All remaining errors are our own.

${ }^{\dagger}$ Corresponding author. Department of Finance, McCombs School of Business, The University of Texas at Austin, 1 University Station B6600, Austin, TX, 78712; email: Jay.Hartzell@mccombs.utexas.edu; phone: (512)471-6779; fax: (512)471-5073. 


\begin{abstract}
While Real Estate Investment Trusts (REITs) have experienced very high growth rates over the past 15 years, the growth in mutual funds that invest in REITs has been even more dramatic. REIT mutual fund returns are typically presented relative to the return on a simple value-weighted REIT index. We ask whether including additional factors when benchmarking funds' returns can improve the explanatory power of the models and offer more precise estimates of alpha. We investigate three sets of REIT-based benchmarks, plus an index of homebuilders' returns. The REIT-based factors are a set of characteristic factors, a set of property-type factors, and a set of statistical factors. Using traditional single index benchmarks, we find that about six percent of the REIT funds exhibit significant positive performance using traditional significance levels, which is more than twice what random chance would predict. However, with the multiple index benchmarks that we prefer, this falls by about half, to about three percent. In addition, we find that these sets of factors and the homebuilders index better explain the month-to-month returns of the REIT mutual funds. This suggests that investors or researchers evaluating REIT mutual fund performance may benefit from a multiple benchmark approach.
\end{abstract}

Keywords: REITs, Mutual Funds, Performance Evaluation 


\section{Introduction}

Over the past several years, the total market value of publicly-traded Real Estate Investment Trusts (REITs) has grown rapidly. In 1990, prior to the Omnibus Budget Reconciliation Act of 1993 that changed REIT ownership rules, there were about 117 REITs, with a total market capitalization of about $\$ 8.5$ billion. In 1994, after the Act, there were 230 REITs with a combined market capitalization of about $\$ 46$ billion. By 2005, while the number of REITs had declined slightly to 208 , the total market capitalization had grown to $\$ 355$ billion, representing a compound annual growth rate of more than $20 \%$.

Along with this growth in the REIT market has been an even greater growth in mutual funds that specialize in REITs. Over the same period, the number of REIT funds has grown from 27 to 235, or more conservatively, the number of unique funds (considering only one share class per fund) has grown from 16 to 132. Meanwhile, the total market capitalization of all REIT funds has grown at a compound annual growth rate of nearly 40\%, from $\$ 1.3$ billion in 1994 to $\$ 50$ billion in $2005 .^{1}$ This growth has outpaced the overall growth in sector funds, suggesting that real estate funds may be special among the set of industry-specific investment vehicles. ${ }^{2}$

Since almost all of these mutual funds are actively managed, there is an interest in evaluating how funds perform relative to more passive benchmarks. Most REIT mutual funds present their performance relative to either the NAREIT or the Dow Jones Wilshire indexes, which means that their goal is to construct a portfolio that is highly correlated with, yet beats, the index. Hence, at least as a starting point, it makes sense to evaluate how the mutual funds perform relative to these value-weighted benchmarks. Our null hypothesis is that the mutual funds will not be able to perform better than these passive benchmarks, which we will test against the alternative that some of the mutual fund managers have superior information or ability that enable them to generate returns that outperform these benchmarks.

\footnotetext{
${ }^{1}$ Note that this total underestimates the total ownership of REITs by real estate-specific asset managers. For example, mutual fund managers such as Cohen \& Steers also manage separate accounts where they purchase REITs for clients, such as pension funds and endowments, but these do not enter the mutual fund database.

${ }^{2}$ Tiwari and Vijh (2004) find 308 unique, non-real estate sector funds as of 1999, with a total market value of $\$ 151$ billion, and this was largely driven by 66 technology funds that were worth $\$ 72$ billion at that time.
} 
Since Roll (1978) researchers have been concerned about the specification of the benchmarks used to evaluate mutual funds. Specifically, the concern is that if inefficient benchmarks are used, passive portfolios will exhibit evidence of abnormal performance. When this is the case, mutual fund managers with no special information or abilities can exhibit what looks like positive performance using these same passive strategies. Our analysis of various REIT portfolios suggests that is indeed the case when traditional benchmarks are used to evaluate mutual fund managers. In particular, REIT funds could have outperformed the NAREIT or the Dow Jones Wilshire indexes by simply concentrating their holdings in smaller capitalization REITs, overweighting industrial REITs, and by including homebuilding stocks in their portfolios. Morever, our analysis suggests that in the 1994 to 2005 period, a number of REIT mutual funds did in fact follow one or more of these strategies. Hence, to evaluate the extent to which REIT mutual fund managers have superior selection skills, one needs to consider benchmarks that account for these systematic deviations from the value-weighted benchmarks.

Along these lines, we consider three multi-factor benchmarks that are composed of REITs. The first benchmark consists of the returns to size and book-to-market characteristic-based factors that are constructed along the lines of the Fama and French (1993) factors, but where the factor returns are from REITs rather than the broader stock market. The second benchmark consists of the returns of portfolios sorted by property type. The third benchmark combines these two and consists of the returns of a set of 13 statistical factor portfolios formed from a factor analysis of a large number of REIT portfolios based on firm size, book-to-market ratio, and property type. In addition to these variables, because REIT mutual funds sometimes invest in non-REIT real estate companies, we consider whether an index of homebuilders' stock returns adds explanatory power.

Our analysis indicates that a value-weighted portfolio of all REIT mutual funds fails to outperform any of our alternative benchmarks net of fees. When we add back fees, we find only weak evidence of average abnormal performance, which is generally not robust to our additional benchmarks. Although the $\mathrm{R}$ square of the single index model is quite high for this value weighted mutual fund portfolio, at 0.977, additional factors do add significantly more explanatory power. Notably, our index of homebuilders' returns is statistically significant in all specifications, suggesting that 
controlling for the performance of real estate firms other than REITs is important.

To evaluate the importance of the benchmark choice for individual mutual funds, we consider two dimensions. The first is the extent to which the benchmarks explain the monthly returns of the funds, i.e., the $\mathrm{R}$ square of the regression of the fund returns on the benchmark portfolios. The general idea is that the benchmark that best explains the monthly returns provides the most reliable indicator of abnormal return. We then evaluate abnormal return as the intercept from the regression of the mutual funds' excess return (over the risk-free rate) on the excess returns of the benchmark portfolios.

Several interesting facts emerge from this analysis. First, consistent with the results on the valueweighted portfolio of all funds, adding an index of homebuilders' returns to any set of benchmark returns increases explanatory power, especially in the left tail of the distribution of $\mathrm{R}$ squares. In addition, adding homebuilders' returns generally reduces funds' estimated abnormal performance, consistent with some funds earning positive abnormal returns relative to REIT-only benchmarks by investing in non-REIT stocks.

We also note that the characteristic-based factors and statistical factors appear to perform better than the property type factors. The property type factors explain less of the variation in returns of the typical fund, are not quite as good in explaining the left tail of the distribution, and produce higher estimated alphas. Both the characteristic and statistical factors allow for return differences due to firm size, while the property type factors do not. Taken together, these results are consistent with the ability to better explain REIT fund performance by controlling for the positive abnormal returns to smaller REITs and homebuilders that we observe using our passive portfolios.

Although our analysis suggests that the benchmark choice has only a modest effect on the measured performance of the value-weighted portfolio of REIT mutual funds, the performance of individual mutual funds can be much more sensitive to the benchmark choice. Based on the traditional single index model, we find that $6.16 \%$ of funds have a positive alpha net of fees with p-values less than 0.05 (based on a two-tailed test), versus the $2.5 \%$ one would expect by chance. However, using the homebuilders index with either our characteristic or statistical factors reduces this percentage by 
about half, to $3.42 \%$. When we consider returns before fees, we find that $26.43 \%$ of funds have positive alphas with p-values less than 0.05 , but this falls to $15 \%$ using our characteristic factors plus the homebuilders index.

To further understand differences in alphas across different benchmarks, when we examine pairwise rank correlations of the alphas from our various alternative benchmark models, we find that 14 of the 28 correlations are less than 0.80 , and the lowest is 0.62 . In addition, there are some examples of individual funds that have positive and statistically significant alphas under the single REIT index model, but negative alphas using the index plus a set of statistical factors. In one extreme case, for the CGM Realty Fund, the single index monthly alpha is 63 basis points before fees ( $\mathrm{t}$ statistic of 2.06), apparently consistent with stock-picking ability. But, the monthly alpha based on the index plus characteristic factors and our homebuilder index is -5 basis points ( $\mathrm{t}$ statistic of $-0.19)$, which does not suggest any abnormal performance, even before fees.

Finally, we examine the relations between fund performance and fund characteristics. Using FamaMacBeth (1973) regressions of returns on characteristics, we find little evidence that fund characteristics are systematically related to performance. But, we do find some indication that the more actively managed funds experienced better performance, and that expense ratios are negatively related to net-of-fees returns. This latter finding is inconsistent with funds earning their fees back via superior stock-picking performance.

Our study is most closely related to the analysis of Kallberg, Liu, and Trzcinka (2000), which studies the performance of 44 REIT mutual funds over the 1986 to 1998 period. In contrast to our results, they find evidence consistent with significant average abnormal performance (net of fees), which they attribute to better performance in down markets. ${ }^{3}$ This difference in overall sector performance suggests that the drastic growth in the sector may have diluted average fund performance. ${ }^{4}$ They also evaluate several single-index REIT benchmarks, and four-factor benchmarks

\footnotetext{
${ }^{3}$ Lin and Yung (2004) also study real estate fund performance, but they conclude that there is no evidence of average abnormal performance over their 1993-2001 sample. Like Kallberg et al., they consider broad stock market factors in addition to a REIT index, and conclude that the stock market factors do not materially impact inference about real estate fund performance.

${ }^{4}$ We obtain qualitatively similar results to Kallberg et al. (2000) when we estimate the alpha on the value-weighted portfolios of all funds over their earlier 1986-1998 time period. Similar to their results, we find some evidence of a significant positive abnormal return using the Dow Jones Wilshire REIT index (at the 0.10 level), but that significance
} 
based on the broader stock market. They find little difference across different REIT indices, and little explanatory power from the factors based on the overall stock market. They conclude that, "a real estate index is the appropriate benchmark for evaluating real estate mutual funds" (page 298). Consistent with our results, they find that more actively managed funds experienced better performance; they also find that larger funds have significantly better performance.

Our study is also related to the large literature on mutual fund performance, which we do not fully review here. The question of whether mutual funds exhibit abnormal performance, and the degree to which abnormal performance persists has been studied by many, including Jensen (1968, 1969), Brown and Goetzmann (1995), Gruber (1996), and Carhart (1997). The use of appropriate benchmarking is central to this question. The broader mutual fund study that is most directly relevant to ours is Grinblatt and Titman (1994), who conclude that inference about fund performance can be strongly influence by the choice of benchmark.

The remainder of the paper is organized as follows. The next section describes our data, including estimates of performance of passive portfolios formed on firm characteristics. Section three discusses the ways in which we construct our various alternative benchmarks and presents the empirical results for alternative benchmark models. Section four discusses the relations between performance and fund characteristics. Section five concludes.

\section{Data}

We construct our dataset using the Center for Research in Security Prices (CRSP) SurvivorshipBias Free U.S. Mutual Fund database. We include all funds that list their detailed objective as "Equity USA Real Estate," and collect monthly returns and fund information for the 1994 through 2005 period. In several of our tests, we present our results for "unique" funds only. For this subset, we collapse multiple share classes into one fund. ${ }^{5}$ We also collect monthly returns for all U.S. equity

is reduced when we use the NAREIT index. Of note, our characteristic factors are still significant over that time period, beyond the NAREIT index, suggesting that firm size and/or book-to-market were important in that period, as well, and that using the NAREIT index does not completely control for these effects.

${ }^{5}$ The algorithm we use for reducing the set of funds is as follows. We consider funds of the same family to be duplicates if the $\mathrm{R}$ square of a regression of one return on the other is greater than 0.999. If they are duplicates, we 
REITs, obtained from CRSP, using securities with the second share class digit of eight.

Table 1 presents summary statistics for the mutual funds and REITs over our sample period. The table documents the rapid growth in the REIT mutual fund industry from 27 funds in 1994 (16 of which are unique), to 123 funds in 1999 (103 unique), to 235 in 2005 (132 unique). Over this period, the number or REITs actually declines somewhat, from 230 to 208, but the market capitalization of REITs grows to nearly eight times its starting level, from $\$ 45.9$ billion in 1994 , to $\$ 129.4$ billion in 1999 , to $\$ 355$ billion in 2005 . The market capitalization of the mutual funds grows even more dramatically (almost 38 times), from $\$ 1.3$ billion in 1994, to $\$ 7.4$ billion in 1999 , to almost $\$ 50$ billion in 2005. As a result, the fraction of the REIT sector held by REIT-specific mutual funds has grown over the 11-year period, from about three percent to over 14 percent.

\subsection{Single Index Benchmarks}

Our starting point for benchmarking fund returns is the Dow Jones Wilshire REIT index, which is a value-weighted index of REIT returns. We considered both the FTSE NAREIT index and the Dow Jones Wilshire REIT index, which were the two most commonly cited benchmarks in a handchecked subsample of our funds' annual reports. ${ }^{6}$ We present results for the Dow Jones Wilshire REIT index for our analysis because it has the highest explanatory power with respect to the funds' returns. We simply call this the "Index" for expositional ease. To calculate excess returns on either our funds, benchmarks, or REITs, we subtract the 30-day Treasury Bill return, as reported by the St. Louis Federal Reserve. We will later consider multi-factor benchmarks that consist of portfolios that are formed based on property types, REIT size, and book to market characteristics.

first select the class that is present at a given date if there is only one. Next, we select the retail class based on the CRSP retail indicator if there is one. Then, we select the lowest-fee fund if there is one. If the funds are the same along all these dimensions, we randomly break the tie.

${ }^{6}$ As an example, consider the 2006 annual report for the Morgan Stanley Real Estate Fund, available at http://sec.gov/Archives/edgar/data/1074111/000110465907008604/a06-26022_1ncsr.htm. The report notes, "Morgan Stanley Real Estate Fund outperformed both the FTSE NAREIT Equity REIT Index and the Lipper Real Estate Funds Index for the 12 months ended November 30, 2006, assuming no deduction of applicable sales charges. The Fund's outperformance during the period was driven primarily by bottom-up stock selection, and top-down sector allocation was also favorable. The Fund's stock selection was especially strong in the mall and office sectors. Within the mall sector, the Fund benefited from its underweight to two of the weakest malls stocks relative to the FTSE NAREIT Equity REIT Index, which had company-specific issues." 


\subsection{The Performance of Passive Portfolios}

Before examining REIT mutual funds we examine whether a variety of passive REIT and homebuilder portfolios can generate abnormal performance relative to the REIT Index over our sample period. If so, then an active portfolio that has exposure to the passive factors that generate excess returns will also generate alpha with respect to a single index model.

To assess the performance of such passive strategies, we estimate the performance of characteristicsorted portfolios that are based on the market capitalization, the book-to-market ratio, and the property types of the REITs. Specifically, we form five size and five book-to-market portfolios by sorting the REITs into the appropriate quintiles. We also construct passive portfolios based on the five main REIT property types (Hotel, Industrial, Office, Residential, and Retail). Finally, we include our portfolio of homebuilders.

For each of these portfolios, we calculate the value-weighted monthly returns in excess of the riskfree rate and regress these excess returns on the excess returns on the Index. The results of these 16 regressions are reported in Table 2. As the table shows, we find strong evidence of a size effect in our sample. Relative to the Dow Jones Wilshire benchmark, the smallest two quintiles experienced significant positive alphas, while the largest quintile has a significant negative alpha. The strongest significance is for the smallest REIT quintile, at 88 basis points per month. This implies that by overweighting smaller REITs in favor of larger ones, a fund manager could have generated positive alpha with respect to a single index benchmark over our 11-year period.

In addition, we find positive abnormal returns for three types of real estate firms. Within the REIT sector, both industrial and retail REITs outperformed the Index, with similar economic and statistical significance. Both of these groups' alphas are about 30 basis points per month. Our index of homebuilders also exhibited strong, significant performance, at 110 basis points per month. Notably, this portfolio has a low $\mathrm{R}$ square with respect to the index at 0.21 (the only lower one among this set is the smallest set of REITs, at 0.20). 


\section{Evaluating REIT Mutual Fund Benchmarks}

The message from Table 2 is that simple passive investment strategies exhibit significant abnormal returns with respect to the single index benchmark over our sample period. This calls for investigating multi-dimensional benchmarks, which we do in our subsequent tests.

\subsection{Characteristic Factors}

Our first set of candidate benchmarks consists of REIT-based versions of the size and book-tomarket factors of Fama and French (1993). To construct these, we sort firms into terciles based on both size (market capitalization) and book-to-market ratio. We then compute $H M L$ as the value-weighted return to the high book-to-market tercile, less the value-weighted return to the low book-to-market tercile. $S M B$ is defined analogously, as the value-weighted returns to the smallest firms' tercile, less the value-weighted returns to the largest firms' tercile. It is worth noting that this approach differs from that used previously in studies examining real estate funds' returns, such as Kallberg, Liu, and Trzcinka (2000) and Lin and Yung (2004), which use the standard Fama-French factors for the overall U.S. stock market (which are constructed excluding REITs).

\subsection{Property Type Factors}

Our next set of candidate benchmark returns consists of returns to property type portfolios. To construct these, we use the SNL classification of each REIT's type to form portfolios of five different property types: Hotel, Industrial, Office, Residential, and Retail. For each property type, we calculate monthly value-weighted returns over the sample period, and then subtract the REIT Index return in each month. ${ }^{7}$

\footnotetext{
${ }^{7}$ While we use SNL's classification of each REIT's property focus, one could imagine using data on specific property holdings to generate more precise estimates. See Geltner and Kluger (1998) for an example of this approach.
} 


\subsection{Statistical Factor Analysis Portfolios}

In order to construct statistical factor analysis portfolios, we need a balanced panel of REIT portfolio returns. We build one by forming portfolios based on the property types of the assets held by the REITs, their market capitalizations, and their book-to-market ratios. Specifically, we first assign REITs into one of five property types: Industrial, Office, Residential, Retail, and "Other" (all other types). We further split each property type portfolio into thirds, by market capitalization and by book-to-market ratio.

The end result of these assignments is a balanced panel of 45 value-weighted portfolios formed on property type, firm size, and book-to-market ratio (five property types, times three size portfolios, times three book-to-market portfolios). From the returns of these portfolios we subtract the return on the REIT Index, and then estimate via maximum likelihood a set of 13 statistical factors. This is the smallest number of factors for which we cannot reject the null that the number of factors is sufficient to explain the variation in the data. Table 3 presents these results in the form of factor loadings for each of the 45 portfolios for the nine factors. For the remainder of the analysis, we use the returns to these 13 statistical factor portfolios as candidate benchmark returns for REIT funds.

As the table shows, the first factor explains seven percent of the variation in the data. The cumulative fraction explained by the first five factors is 30.8 percent, and this reaches 52 percent by the thirteenth factor. Thus, even starting with a set of 45 portfolios rather than individual REITs, a relatively large number of factors is required to explain most of the variation in REIT returns, consistent with differences in returns due to firm size, property types, and book-to-market, rather than simply a common U.S. real estate factor. Unfortunately, the loadings themselves do not reveal any obvious patterns.

\subsection{Homebuilder Factor}

For our final candidate benchmark return, we use a portfolio of homebuilder stocks. We calculate the value-weighted monthly returns for all firms on CRSP in SIC code 1531 (Operative Builders) 
and subtract the REIT Index return, which we then label, Homebuilders. We consider multi-factor benchmarks that include this factor portfolio along with the other benchmark portfolios described above.

\subsection{Using Alternative Benchmarks to Explain Individual REIT Returns}

We begin by investigating the degree to which our alternative benchmarks can explain the returns to individual REITs. Table 4 reports regressions of monthly excess returns for individual REITs on the excess returns of the REIT Index, and various factor models. In this table, and in subsequent tables with individual mutual fund returns, we require a minimum of 24 months of returns for a REIT (or fund) to be included. The results are consistent with the factor analysis in the sense that individual REITs exhibit a large degree of idiosynchratic variation. For the mean (median) firm, the Index alone explains only 20 percent (16 percent) of the variation. Among the alternative additional benchmarks, the statistical factors appear to add the most explanatory power; the mean and median $\mathrm{R}$ square for these factors is about 0.31 . Even though our focus is not on the alphas of individual REITs, it is interesting to note that the typical alphas generated by the single index models are larger than those calculated by the other models. As we show below, this difference in estimated alphas also appears at the mutual fund level.

\subsection{Using Alternative Benchmarks to Explain Returns to the REIT Fund Sector}

We now turn to the question of the ability of these alternative benchmarks to explain the returns of REIT mutual funds. To do this, we run regressions of the monthly excess return on a valueweighted portfolio of all of funds on our various single index and multiple factor benchmarks. In Table 5, we calculate the average return using the actual returns investors in the funds experienced (i.e., net of fees), while in Table 6, we use returns before fees (i.e., we add them back to the net returns).

Model 1 in Table 5 presents the results for a regression using only the Dow Jones Wilshire REIT 
Index. These results indicate that the single factor REIT Index model explains a great deal of the variation in the value-weighted funds' returns; the $\mathrm{R}$ square in the regression is 0.977 . By way of comparison, Model 2 presents the results for a similar regression using NAREIT as the single index. This model has a slightly lower $\mathrm{R}$ square of about 0.961 , so we focus on the Dow Jones Wilshire REIT Index for the remainder of the analysis. The point estimate of the alpha in this single index model is very small, at -0.9 basis points per month (for the Dow Jones Wilshire Index), and is insignificantly different from zero. ${ }^{8}$ This is in contrast to the results of Kallberg, Liu, and Trczinka (2000), who find positive abnormal returns for the average REIT fund in their sample. ${ }^{9}$ This appears sample specific; if we run this same regression over their sample period (1986 to 1998), we find some evidence of abnormal performance (at the 0.10 level using two-tailed tests), consistent with their results. ${ }^{10}$ Kallberg et al. argue that the positive abnormal performance may be due to an informational advantage possessed by REIT fund managers. The insignificant results in the recent time period after the explosive growth in funds is consistent with this advantage being reduced over time, and with the dilution of the average advantage due to the entry of new managers who may be less skilled in evaluating REITs.

In Model 3, we add Homebuilders to our base model. As the results indicate, homebuilder returns have significant incremental explanatory power. The adjusted R square in the regression increases to 0.982 , and the t statistic on Homebuilders is very significant, at 6.49 , which is consistent with REIT fund managers investing in some non-REIT real estate stocks. This is a consistent theme throughout the table - no matter what set of REIT-based benchmarks is used, Homebuilders is still significant, and its inclusion increases the model's adjusted $\mathrm{R}$ square. This suggests that

\footnotetext{
${ }^{8}$ This is inconsistent with the results of Lin and Yung (2004), who find a significant alpha of -46 basis points using a value-weighted average of real estate mutual funds over the 1997 to 2001 period. They use the NAREIT index, and find a lower $\mathrm{R}$ square than ours, at 0.90 versus our 0.98 . They also find no additional explanatory power beyond the NAREIT index for broad stock-market based Fama-French and momentum factors. This suggests that their results may be sample or benchmark specific.

${ }^{9}$ Our work is also related to previous studies of the performance of institutionally managed real estate investments other than mutual funds, such as commingled real estate funds (CREFs). For recent evidence of positive abnormal performance in a sample of CREFs, see Gallo, Lockwood, and Rodriguez (2006). They use a single-index model to explain CREF returns, where the index is based on property-level returns, but they also investigate the addition of regional or property type indexes and find similar results. For prior evidence on CREF performance, see Myer, Webb and He (1997), and Myer and Webb (1993).

${ }^{10}$ Consistent with Kallberg, Liu and Trczinka (2000), we find lower, insignificant alphas when we use the NAREIT index instead of the Dow Jones Wilshire Index. It is worth noting however, that our characteristic factors are still statistically significant in their time period using NAREIT as the market index, even though NAREIT includes smaller REITs than the Dow Jones Wilshire Index.
} 
benchmarking these funds' returns can be improved by including such a non-REIT proxy.

In Models 4, 6, and 8, we successively consider adding our characteristic factors, property type factors, and statistical factors to the single index. Models 5, 7, and 9 present identical specifications, respectively, except for the addition of Homebuilders. The property type regressions offer the highest adjusted R squares (0.980 without Homebuilders), although all of the alternatives improve the explanatory power relative to the single index model (adjusted $\mathrm{R}$ squares of 0.978 for the characteristic factors and 0.979 for the statistical factors, respectively). F-statistics for tests of the joint hypothesis that all of the coefficients except for that on the Index (and Homebuilders, if it is included) are zero, are also the highest for the property type factors, although they are also significant in the statistical factor and characteristic factor regressions, without Homebuilders. Across models, there is no evidence of significant positive abnormal performance. The only significant alphas are in Models 5 and 9, and their estimates are negative nine and negative eight basis points per month, respectively.

In Table 6, we present results from identical specifications, except we use the value-weighted excess return on all of the funds before fees (i.e., we add back fees to the CRSP returns by adding $\frac{1}{12}$ of the annual expense ratio to each month's return). As one would expect, the explanatory power of the various models is virtually unchanged. Of more interest is the estimated abnormal performance across different specifications. We find significant positive abnormal performance in specifications using the single indexes (Dow Jones Wilshire or NAREIT), statistical factors and property type factors. The magnitude of this performance is plausible, at 10 basis points per month (about 1.2 percent per year) for the Dow Jones Wilshire single index model. But, the estimated abnormal performance is reduced in every alternative by the addition of Homebuilders; the estimated alpha is not signficant in any model where this is included. In addition, the alpha is insignificant in the characteristic factor model, although the point estimate is not very different from the single index model (seven basis points versus 10 basis points per month). Taken together, the results suggest that the average REIT fund exhibits some abnormal performance, but that the performance is offset by expenses. They are also consistent with the results of Table 2, which suggest that fund managers add alpha in this sample by overweighting smaller REITs and buying homebuilders' stocks. 


\subsection{Using Alternative Benchmarks to Explain Individual REIT Fund Returns}

While these results suggest that additional factors beyond a single index can more precisely estimate abnormal performance for the group of REIT funds as a whole, our ultimate question is whether these alternative benchmarks provide better assessments of the performance of individual funds. To address this, we run separate time series regressions of each fund's excess monthly returns on our same alternatives (the single index, plus characteristic factors, property type factors, and statistical factors, with and without Homebuilders). In Table 7, for each of these alternatives, we summarize the distribution of three key statistics across the sample of funds: the adjusted $\mathrm{R}$ square, alpha, and the t-statistic for the alpha. We also present additional statistics regarding the distribution of alphas: the cross-sectional standard deviation of estimated alphas, and the percentage of alphas that are significantly positive and negative. For these significance calculations, we tabulate the fraction of alphas with p-values that are less than or equal to 0.05 , separated by whether they are positive or negative. Note that since these p-values are based on two-sided tests, random chance would predict that $2.5 \%$ of alphas are significantly positive, with another $2.5 \%$ significantly negative.

First, as one can see from the table, the benchmarks do a very good job of explaining the variation in returns of the typical fund. The single index model produces a mean (median) $\mathrm{R}$ square of 0.903 (0.955). By way of comparison, in their 1986 to 1998 sample, Kallberg, Liu, and Trczinka (2000) find a mean (median) R square of 0.851 (0.91) with respect to the Wilshire REIT index. This suggests that typical REIT funds more closely track this index than they did previously.

Benchmarks that more accurately explain monthly returns will produce more precise estimates of fund performance. In addition to considering the improved explanatory power for a typical fund, we also consider whether the additional factors increase the $\mathrm{R}$ squares of the funds for which the single index model performs most poorly. In the middle of the distribution, the results are consistent with what we found for the value-weighted index of all funds. We find that all of the multiple factor models improve explanatory power beyond the single index; median and mean R square are higher in all of these alternatives. Based solely on this criterion, the statistical factors with Homebuilders 
offer the highest mean and median adjusted $\mathrm{R}$ square (0.935 and 0.964, respectively). The addition of Homebuilders also improves explanatory power for the typical fund. For explaining the left-tail outliers, the statistical factor model with Homebuilders again offers the biggest improvement, with a 10th percentile adjusted $\mathrm{R}$ square of 0.853 versus 0.744 for the single index model.

In addition to improvements in $\mathrm{R}$ squares, we also care about estimated alphas and their statistical significance. The mean (median) monthly alpha using the single index is only about $-0.1(-0.01)$ basis points. In contrast, the mean (median) alpha using the same benchmark reported in Kallberg, Liu, and Trczinka (2000) for their earlier time period is 18 basis points (9 basis points) per month. This difference across samples is not surprising given our results on the alpha of the value-weighted portfolio of all funds.

Based on the standard deviations of alphas across different benchmarks, the multiple index models do not appear to reduce the variation in alphas across funds. While the characteristic factors model has the lowest standard deviation (0.00178), the single index model's standard deviation is the next lowest (0.00182). However, if one looks at reductions in the right tail of estimated alphas, and the extreme $t$ statistics, the models using statistical factors and characteristic factors with Homebuilders appear to work well. The 90th percentile of alpha is reduced from 21 basis points per month in the single index model to 13 basis points for the statistical factors with Homebuilders model, and to 10 basis points in the characteristic factors with Homebuilders model. The t statistic drops from 1.52 to 1.24 or to 1.06 , respectively, at the same point in the distribution. At the middle of the distribution, the estimated alphas from these two alternatives also appear to be more conservative than the single index. Compared to the average and median alphas based on the single index model that were basically zero, when one adds the statistical factors and Homebuilders, the mean (median) alpha is -8 basis points (-7 basis points). Similarly, for the models using the characteristic factors and Homebuilders, the mean (median) alpha is -11 basis points (-8 basis points). Typical alphas using the property type factors are higher than those based on the characteristic or statistical factors when Homebuilders is not included, consistent with an important firm size component of returns over this sample.

These reductions in right-tail alphas can also be seen by examining the fraction of significant positive 
alphas across models. For the single index model, $6.16 \%$ of alphas are positive and significant at the 0.05 level (using two-tailed tests), which is more than twice what would be expected based on random chance. Three alternative models reduce this proportion by almost half, to $3.42 \%$ : the single index model with Homebuilders, the characteristic factors with Homebuilders, and the statistical factors with Homebuilders. The characteristic factors with Homebuilders produces the largest fraction with estimated negative significant performance, at $18.49 \%$, versus $10.27 \%$ for the single index model.

Figure 1 presents box-and-whisker plots of the alphas of the single Index model, as well as each alternative model including Homebuilders. In the figure, the solid middle line represents the median alpha, while the upper and lower edges of each box represent the first- and third quartiles, respectively. The dashed vertical lines (the whiskers) extend 1.5 times the interquartile range (the length of the box) from the edges, while any remaining outliers beyond this distance are plotted individually as circles. As the figure shows, the Index-only model generates alphas that are noticeably higher than any of the alternative models that include the Homebuilders index, both in terms of the medians and the left tail of the distribution. Among the models that include Homebuilders, median alphas are slightly smaller using the characteristic or statistical factors. In addition, these two models result in tighter distributions than the other alternatives.

Table 8 presents the same information as Table 7, but using returns to funds before fees (i.e., with $\frac{1}{12}$ of the annual expense ratio added to each fund's monthly return). Since fees do not vary much with the factors, we find little difference in explanatory power. Of more interest are the estimated alphas. Here, again, the combinations of the characteristic or statistical factors and Homebuilders appear to offer the most conservative approaches. For example, using the single index, the 75 th percentile of the alpha distribution is 20 basis points per month, while the t statistic at that percentile is 2.03. In contrast, using characteristic factors plus Homebuilders, the 75th percentile alpha and t-statistic are 16 basis points and 1.62, respectively. For the statistical factors plus Homebuilders, we also see a reduction in estimated abnormal performance, although not quite as large. The estimated alpha and t-statistic at those same cutoffs are 17 basis points and 1.77, respectively. However, while looking at the percentage of funds with significantly positive alphas, the statistical factors (plus 
Homebuilders) is the most conservative. While $26.43 \%$ of funds have positive alphas with p-values of less than or equal to 0.05 , this drops to $15 \%$ for the statistical factors model with Homebuilders (compared to $19.29 \%$ for the characteristic factors with Homebuilders). The property type factors plus Homebuilders offers the smallest reduction in alphas, with a 75 th percentile estimated alpha and t-statistic of 22 basis points and 1.89, respectively.

Comparing the results of Tables 7 and 8 , we find evidence consistent with a fairly large percentage of REIT fund managers producing significant alpha before fees. Even using our most conservative model, our estimates imply that $15 \%$ of funds had positive significant alphas, much more than the $2.5 \%$ level one would expect by chance. But, after fees, the incidence of abnormal positive performance is much more in line with statistical norms, at $3.42 \%$ In contrast, the incidence of negative abnormal performance before fees is in line with random chance (around three percent, depending on the model used), but after fees, this becomes as high as $18.49 \%$.

While these results help us understand the distribution of alphas across various model choices, they do not say anything about how the different benchmarks affect estimated alphas for a particular fund. To assess this, we first check how the top ten funds in terms of performance using the single index model faired against our multiple benchmark models. In Table 9, we present the alphas across different models that include Homebuilders for the 10 funds with the largest alphas from the single index model. For all of the funds, the multiple benchmarks produce more conservative estimates of performance. For example, for the top fund, the Third Avenue Real Estate Fund, the estimated alpha is 71 basis points per month for the single index model, but this falls to 44 basis points using the characteristic factors with Homebuilders. More generally, for half of this subsample, including Third Avenue, the benchmark choice does not matter much, but for the other half, it matters a lot. For five of the 10 funds, the estimated alphas are consistently positive and of similar maginitude. But, for the other five, alphas are actually negative for the characteristic factor model with Homebuilders.

To further investigate changes in alpha ranks across models, we calculate the Spearman rank correlations of the alphas from our eight candidate models (single index, plus characteristic factors, property type factors, or statistical factors, with or without Homebuilders). These rank correlations 
are presented in Table 10. Several facts emerge from data. First, the addition of the homebuilders returns appears to have important effects beyond the single index model. The rank correlation between the single index model and the single index model with homebuilders is only 0.83 , and this falls to between 0.66 and 0.73 for the other factors plus homebuilders. Second, by looking at the correlation of alphas between a set of factors without homebuilders and that same set with homebuilders, it appears that including homebuilders has the biggest impact on the ranks of alphas of the single index model (rank correlation of 0.83) and the statistical factors (rank correlation of 0.82). Finally, given the performance of the characteristic and statistical factors with Homebuilders models in the previous tables, it is useful to examine those models' rank correlations specifically. As one might expect, the statistical factors plus Homebuilders model appears to capture parts of the property type and characteristic factors. The rank correlation between the statistical factor model alphas and either the property type factor alphas or the characteristic factor alphas are higher than that between the property type and characteristic factors (0.86 and 0.82 , versus 0.77$)$.

\section{Performance as a Function of Fund Characteristics}

We conclude our analysis by investigating the relations between fund performance and various fund characteristics. While we find no evidence of abnormal performance for a typical fund, it may be that some fund performance is related to characteristics such as fund size, expenses, and the degree to which the fund appears to be actively managed. To test for this, we conduct regressions in the style of Fama-MacBeth (1973). For each year in the sample, we run a cross-sectional regression of fund returns (net of fees, or with fees added back) on fund characteristics. We then present the average coefficient and $\mathrm{t}$ statistic for each variable across the time series, where the $\mathrm{t}$ statistic is calculated based on the ratio of the average coefficient to the time-series standard deviation of the coefficient. This technique allows for cross-sectional correlation in performance at any given point in time, as the statistical significance relies on time series variation.

The characteristics we investigate are firm size (the natural logarithm of the fund's net asset value as of the end of the previous year, denoted $\left.\operatorname{Ln}\left(S_{i z e_{t-1}}\right)\right)$, the total expense ratio (Expenses), the 
annual fund turnover (as reported on CRSP, denoted Turnover), the total number of holdings of the fund (Holdings), and an indicator variable for funds with loads (Load). Kallberg et al. (2000) find evidence consistent with larger funds and more actively managed funds exhibiting greater performance. If this were true in our sample, we would expect a positive coefficient on our fund size variable, a positive coefficient on Turnover, and a negative coefficient on Holdings (as more actively managed funds would hold fewer REITs than the index, and would trade more aggressively). We are also interested in the coefficients on the Expenses variable across the two regressions net of fees and with fees added back. If fees are uncorrelated with stock-picking ability, then we would expect an insignificant coefficient for Expenses in the regression with fees added back to returns, and a coefficient of -1.0 on expenses in the regression using returns net of fees. In contrast, if expenses were strictly based on stock-picking ability and passed through to investors accordingly, we would expect a coefficient of 1.0 in the before-expenses regression, and a coefficient of zero in the net-of-expenses regression.

The results of these tests are presented in Table 11. Unfortunately, we are unable to explain much of the variation in returns across our sample, perhaps due to a lack of power given the small number of years. We do find a significant negative coefficient on expenses in the net-of-fees regression and an insignificant coefficient in the before-fees regression, which are more consistent with a lack of correlation between stock picking and expense ratios. There is some marginal evidence of a relation between active management and performance; the point estimate on Turnover is positive and the point estimate on Holdings is negative, and the $\mathrm{p}$ value on the former is about 0.12 in a two-tailed test. We find little evidence of relations between performance and fund size or the presence of a load.

\section{Conclusion}

REIT mutual funds have experienced a tremendous recent growth in popularity. These funds are actively managed and charge substantial fees that reflect the possibility that their active management will generate returns that exceed the returns that can be generated with passive investment 
strategies. In order to evaluate whether these funds do in fact generate abnormal returns, we need benchmark portfolios that allow us to evaluate the marginal benefits of active portfolio management. This study examines these indexes and considers some multiple factor benchmarks that can potentially provide better assessments of the performance of REIT mutual funds.

Our study first documents that over our sample period, simple passive portfolios that concentrated on smaller REITs, or non-REIT real estate firms (homebuilders) generate significant alphas with respect to the commonly used single REIT index benchmarks. This suggests that alternative benchmarks may add explanatory power beyond the index, which should lead to more precise estimates of abnormal performance. We investigate three sets of REIT-based benchmarks, plus an index of homebuilders' returns. The REIT-based factors are a set of statistical factors, a set of property-type factors, and a set of Fama-French type characteristic factors that are zero-cost portfolios of REITs.

Our statistical factors and these REIT-based characteristic factors, when combined with homebuilders' returns and the REIT index, appear to offer the most attractive traits as benchmarks for fund returns. These models do the best job in improving the explanatory power for the funds with the lowest $\mathrm{R}$ squares based on the Index alone. Furthermore, in terms of estimating alphas, these models appear more conservative and help explain extreme outliers in terms of positive abnormal performance based on the single index. Consistent with the evidence of abnormal returns of passive portfolios, our results suggest that including benchmarks that are sensitive to firm size, book-to-market, and non-REIT returns materially affects inference about fund performance. 


\section{References}

[1] Brown, S.J. and W.N. Goetzmann. 1995. Performance Persistence. Journal of Finance 50: 679-698.

[2] Carhart, M. M. 1997. On Persistence in Mutual Fund Performance. Journal of Finance 52: $57-82$.

[3] Fama, E.F. and K.R. French. 1993. Common Risk Factors in the Return on Bonds and Stocks. Journal of Financial Economics 33: 3-53.

[4] Fama, E.F. and J.D. MacBeth. 1973. Risk, Return, and Equilibrium: Empirical Tests. Journal of Political Economy 81: 607-636.

[5] Gallo, J.G., L.J. Lockwood and M. Rodriguez. 2006. Differentiating CREF Performance. Real Estate Economics 34: 173-209.

[6] Geltner, D. and B. Kluger. 1998. REIT-Based Pure-Play Portfolios: The Case of Property Types. Real Estate Economics 26: 581-612.

[7] Grinblatt, M. and S. Titman. 1994. A Study of Monthly Mutual Fund Returns and Performance Evaluation Techniques. Journal of Financial and Quantitative Analysis 29: 419-444.

[8] Gruber, M.J. 1996. Another Puzzle: The Growth in Actively Managed Mutual Funds. Journal of Finance 51: 783-810.

[9] Jensen, M. 1968. The Performance of Mutual Funds in the Period 1945-1964. Journal of Finance 23: 389-416.

[10] Jensen, M. 1969. Risk, the Pricing of Capital Assets, and the Evaluation of Investment Portfolios. Journal of Business 42: 167-247.

[11] Kallberg, J.G., C.L. Liu and C. Trzcinka. 2000. The Value Added from Investment Managers: An Examination of Funds of REITs. Journal of Financial and Quantitative Analysis 35: 387408. 
[12] Lin, C.Y. and K. Yung. 2004. Real Estate Mutual Funds: Performance and Persistence. Journal of Real Estate Research 26(1): 69-93.

[13] Myer, F.C.N. and J.R. Webb. 1993. The Effect of Benchmark Choice on Risk-Adjusted Performance Measures for Commingled Real Estate Funds. Journal of Real Estate Research 8(2): 189-203.

[14] Myer, F.C.N., J.R. Webb and L.T. He. 1997. Issues in Measuring Performance of Commingled Real Estate Funds. Journal of Real Estate Portfolio Management 3(2): 79-85.

[15] Roll, R. 1978. Ambiguity when Performance is Measured by the Securities Market Line. Journal of Finance 33: 1051-1069.

[16] Tiwari, A. and A.M. Vijh. 2004. Sector Fund Performance: Analysis of Cash Flow Volatility and Returns. Working Paper. University of Iowa. 
Table 1: Summary of the Number and Market Captialization of Mutual Funds and REITs. This table presents the number of mutual funds that specialize in US Equity Real Estate as well as their total market capitalizations at the end of each year of our sample. Number of Unique Funds represents the number of mutual funds after we join funds in the same family which seem to hold the same portfolio. As a comparison, we also present for each year the number of publicly traded REITs and their total market capitalizations.

\begin{tabular}{cccccc}
\hline \hline Year & $\begin{array}{c}\text { Number } \\
\text { of Funds }\end{array}$ & $\begin{array}{c}\text { Number } \\
\text { of Unique Funds }\end{array}$ & $\begin{array}{c}\text { Fund } \\
\text { Market Cap }\end{array}$ & $\begin{array}{c}\text { Number } \\
\text { of REITs }\end{array}$ & $\begin{array}{c}\text { REIT } \\
\text { Market Cap }\end{array}$ \\
\hline 1994 & 27 & 16 & 1,325 & 230 & 45,862 \\
1995 & 37 & 37 & 2,019 & 231 & 60,175 \\
1996 & 54 & 53 & 5,710 & 215 & 91,069 \\
1997 & 72 & 64 & 11,964 & 226 & 138,868 \\
1998 & 101 & 90 & 8,807 & 228 & 141,646 \\
1999 & 123 & 103 & 7,436 & 221 & 129,404 \\
2000 & 135 & 108 & 11,106 & 204 & 145,098 \\
2001 & 144 & 107 & 12,072 & 197 & 159,644 \\
2002 & 134 & 105 & 14,974 & 191 & 168,193 \\
2003 & 162 & 125 & 25,888 & 187 & 235,617 \\
2004 & 216 & 128 & 41,275 & 204 & 324,879 \\
2005 & 235 & 132 & 49,967 & 208 & 355,046 \\
\hline \hline
\end{tabular}

All market capitalization figures are in millions of U.S. Dollars. 
Table 2: R squares, Alphas, and T-statistics for Passive Portfolios Formed Using Individual Factors. This table presents $\mathrm{R}$ squares, alphas, and t-statistics of alphas from a set of univariate regressions of each individual factor on the index. The factors used are size quintile portfolios of REITs (numbered from smallest to largest), book-to-market ratio quintile portfolios (numbered the same way), the portfolio of homebuilders, and the individual property-type portfolios.

\begin{tabular}{lccc}
\hline \hline & R square & alpha & t-statistic \\
\hline Size.1 & 0.1962 & 0.0088 & $3.6599^{* * *}$ \\
Size.2 & 0.4787 & 0.0051 & $2.1977^{*}$ \\
Size.3 & 0.7142 & 0.0025 & 1.3600 \\
Size.4 & 0.8667 & 0.0018 & 1.4687 \\
Size.5 & 0.9731 & -0.0012 & $-2.0187^{*}$ \\
BE.ME.1 & 0.8782 & -0.0001 & -0.0765 \\
BE.ME.2 & 0.9165 & -0.0008 & -0.7620 \\
BE.ME.3 & 0.8553 & 0.0010 & 0.7882 \\
BE.ME.4 & 0.6268 & 0.0009 & 0.3722 \\
BE.ME.5 & 0.4628 & 0.0044 & 1.4642 \\
Homebuilders & 0.2139 & 0.0110 & $2.0508^{*}$ \\
Hotel & 0.4837 & -0.0040 & -0.9023 \\
Industrial & 0.8146 & 0.0034 & $2.1805^{*}$ \\
Office & 0.8553 & 0.0012 & 0.8575 \\
Residential & 0.8533 & 0.0004 & 0.3284 \\
Retail & 0.8239 & 0.0029 & $2.0239^{*}$ \\
\hline \hline
\end{tabular}

$\circ: p<10 \%$; $: p<5 \%$; ${ }^{* *}: p<1 \%$; ${ }^{* * *}: p<0.1 \%$. 





Table 4: Adjusted R squares, Alphas and T-statistics of Alphas for REITs.

This table presents means, 10th percentiles, 25th percentiles, medians, 75th percentiles, and 90th percentiles of the distributions of adjusted $\mathrm{R}$ squares, alphas, and t-statistics of alphas, for excess returns to individual REITs with respect to a variety of explanatory variables, as well as the standard deviation of the alphas, and the percentage of firms that realize alphas that are positive and significant at the $5 \%$ level (2-tailed test). The explanatory variables consist of the excess returns to the Dow-Jones Wilshire index, a 3-factor model of the index plus two firm-characteristic factors, namely a size- and a book-to-market factor computed using only REITs, a 6-factor model of the index and six property-type portfolios, and a 14-factor model of the index augmented by the 13 statistical factors from the triple-sorted portfolios presented in table 3. Each model in turn is also augmented by the index of homebuilders.

\begin{tabular}{|c|c|c|c|c|c|c|}
\hline Figure & Mean & $10 \%$ & $25 \%$ & Median & $75 \%$ & $90 \%$ \\
\hline \multicolumn{7}{|c|}{ Index Only } \\
\hline Adj. R square & 0.205286 & -0.009296 & 0.025764 & 0.163032 & 0.354748 & 0.508471 \\
\hline Alpha & 0.003892 & -0.005596 & 0.000099 & 0.003679 & 0.007853 & 0.013519 \\
\hline T-stats & 0.605821 & -0.630753 & 0.007579 & 0.656272 & 1.226306 & 1.796753 \\
\hline$\sigma_{\alpha}=0.01318$ & \multicolumn{6}{|c|}{$\%$ of positive (negative) alphas with p-values $\leq 0.05: 5.99 \%(0.63 \%)$} \\
\hline \multicolumn{7}{|c|}{ Index + Homebuilders } \\
\hline Adj. R square & 0.208614 & -0.014462 & 0.033619 & 0.168331 & 0.360205 & 0.511131 \\
\hline Alpha & 0.003384 & -0.007998 & -0.000439 & 0.003564 & 0.007395 & 0.013416 \\
\hline T-stats & 0.53421 & -0.83658 & -0.066907 & 0.580509 & 1.212634 & 1.797785 \\
\hline$\sigma_{\alpha}=0.01409$ & \multicolumn{6}{|c|}{$\%$ of positive (negative) alphas with p-values $\leq 0.05: 5.68 \%(0.95 \%)$} \\
\hline \multicolumn{7}{|c|}{ Index + Characteristic Factors } \\
\hline Adj. R square & 0.249266 & 0.017424 & 0.078237 & 0.236815 & 0.392258 & 0.516362 \\
\hline Alpha & 0.000499 & -0.010796 & -0.002717 & 0.00201 & 0.005384 & 0.010171 \\
\hline T-stats & 0.267926 & -1.048414 & -0.410795 & 0.33569 & 0.99398 & 1.477133 \\
\hline$\sigma_{\alpha}=0.01412$ & \multicolumn{6}{|c|}{$\%$ of positive (negative) alphas with p-values $\leq 0.05: 5.05 \%(1.58 \%)$} \\
\hline \multicolumn{7}{|c|}{ Index + Characteristic Factors + Homebuilders } \\
\hline Adj. R square & 0.249244 & 0.018449 & 0.088609 & 0.238809 & 0.388373 & 0.516899 \\
\hline Alpha & 0.00044 & -0.01085 & -0.002816 & 0.001975 & 0.005499 & 0.010457 \\
\hline T-stats & 0.263811 & -1.026507 & -0.351461 & 0.272254 & 0.98661 & 1.4466 \\
\hline$\sigma_{\alpha}=0.01457$ & \multicolumn{6}{|c|}{$\%$ of positive (negative) alphas with p-values $\leq 0.05: 3.79 \%(2.21 \%)$} \\
\hline \multicolumn{7}{|c|}{ Index + Property Type Factors } \\
\hline Adj. R square & 0.247604 & -0.030007 & 0.056630 & 0.204076 & 0.417073 & 0.573246 \\
\hline Alpha & 0.003438 & -0.008460 & -0.001448 & 0.002158 & 0.006847 & 0.014118 \\
\hline T-stats & 0.371435 & -0.737833 & -0.297614 & 0.331761 & 1.00171 & 1.681147 \\
\hline$\sigma_{\alpha}=0.0179$ & \multicolumn{6}{|c|}{$\%$ of positive (negative) alphas with p-values $\leq 0.05: 4.1 \%(2.21 \%)$} \\
\hline \multicolumn{7}{|c|}{ Index + Property Type Factors + Homebuilders } \\
\hline Adj. R square & 0.247824 & -0.031541 & 0.056965 & 0.212023 & 0.418569 & 0.578296 \\
\hline Alpha & 0.003597 & -0.008281 & -0.001690 & 0.001995 & 0.006516 & 0.014697 \\
\hline T-stats & 0.362862 & -0.842567 & -0.267194 & 0.314807 & 0.998753 & 1.617645 \\
\hline$\sigma_{\alpha}=0.01847$ & \multicolumn{6}{|c|}{$\%$ of positive (negative) alphas with p-values $\leq 0.05: 4.1 \%(2.84 \%)$} \\
\hline \multicolumn{7}{|c|}{ Index + Statistical Factors } \\
\hline Adj. R square & 0.308226 & -0.006205 & 0.144116 & 0.311309 & 0.495487 & 0.609606 \\
\hline Alpha & 0.002145 & -0.007906 & -0.00182 & 0.002226 & 0.006482 & 0.013542 \\
\hline T-stats & 0.377583 & -0.827453 & -0.258906 & 0.37127 & 0.99132 & 1.615394 \\
\hline$\sigma_{\alpha}=0.01356$ & \multicolumn{6}{|c|}{$\%$ of positive (negative) alphas with p-values $\leq 0.05: 3.47 \%(0.63 \%)$} \\
\hline \multicolumn{7}{|c|}{ Index + Statistical Factors + Homebuilders } \\
\hline Adj. R square & 0.30833 & 0.005636 & 0.129111 & 0.312276 & 0.490031 & 0.608221 \\
\hline Alpha & 0.00226 & -0.008158 & -0.001813 & 0.002334 & 0.006579 & 0.013534 \\
\hline T-stats & 0.358011 & -0.928518 & -0.224289 & 0.370016 & 0.940154 & 1.555345 \\
\hline$\sigma_{\alpha}=0.01405$ & \multicolumn{6}{|c|}{$\%$ of positive (negative) alphas with p-values $\leq 0.05: 4.42 \%(0.95 \%)$} \\
\hline
\end{tabular}

Number of firms: 317 


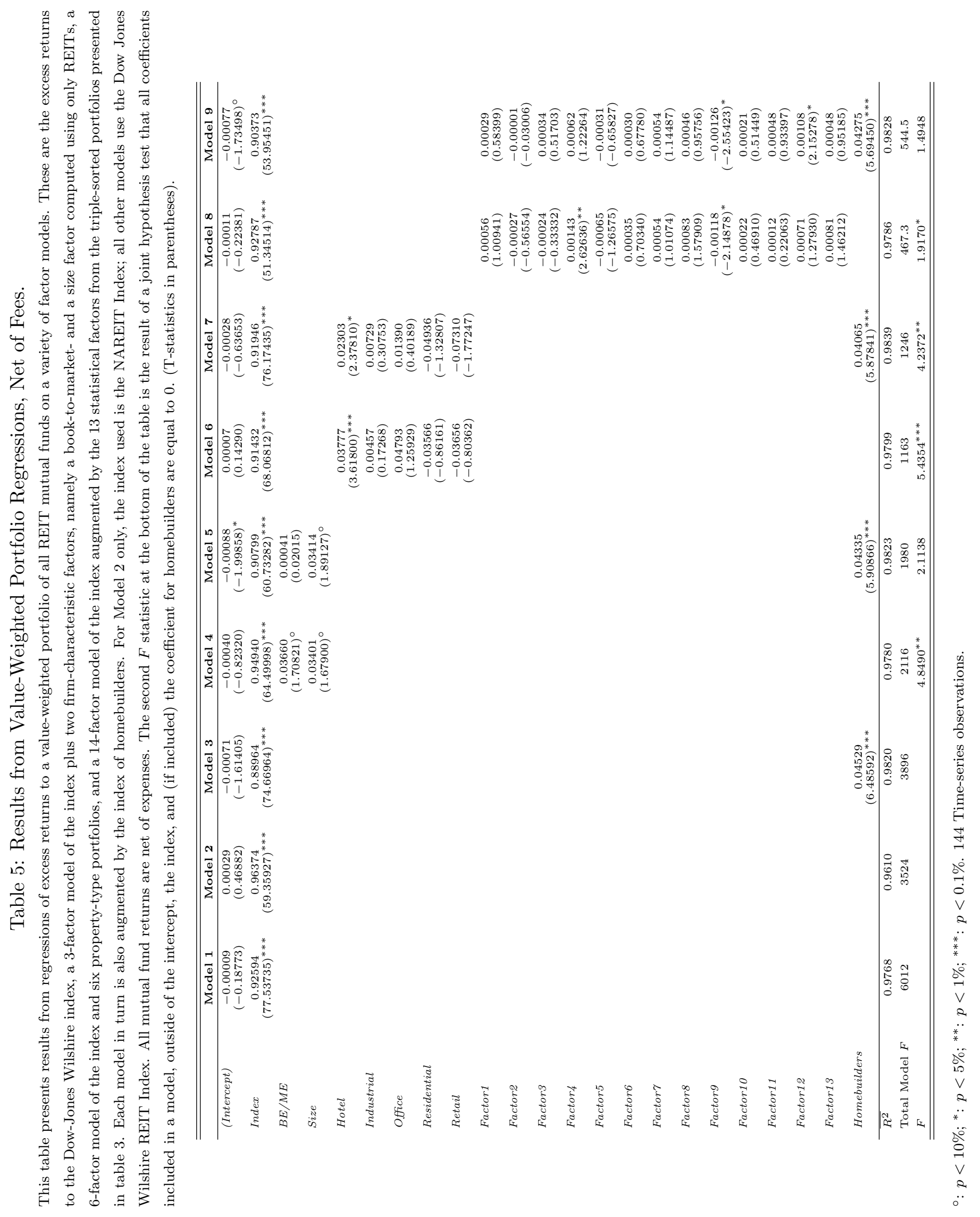




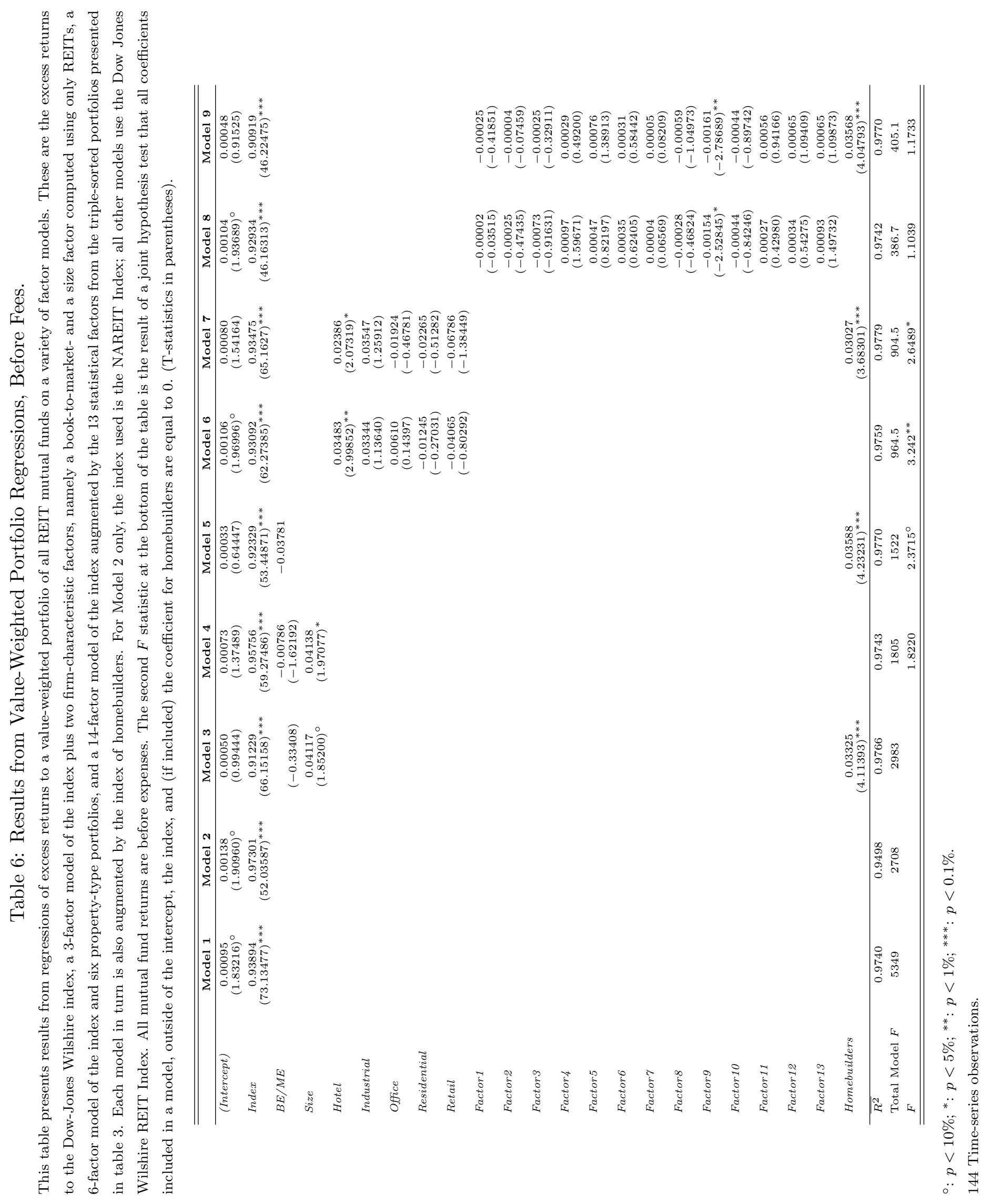


Table 7: Adjusted R squares, Alphas and T-statistics of Alphas for REIT Mutual Funds, Net of Fees.

This table presents means, 10th percentiles, 25th percentiles, medians, 75th percentiles, and 90th percentiles of the distributions of adjusted $\mathrm{R}$ squares, alphas, and t-statistics of alphas, for excess returns to individual REIT mutual funds with respect to a variety of explanatory variables, as well as the standard deviation of the alphas, and the percentage of funds that realize alphas that are positive and significant at the $5 \%$ level. The variables consist of the excess returns to the Dow-Jones Wilshire index, a 3 -factor model of the index plus two firm-characteristic factors, namely a book-to-market- and a size factor computed using only REITs, a 6 -factor model of the index and six property-type portfolios, and a 14-factor model of the index augmented by the 13 statistical factors from the triple-sorted portfolios presented in table 3. Each model in turn is also augmented by the index of homebuilders. For our sample of funds, we combine funds within the same family which seem to hold the same portfolio. All returns are net of expenses.

\begin{tabular}{|c|c|c|c|c|c|c|}
\hline Figure & Mean & $10 \%$ & $25 \%$ & Median & $75 \%$ & $90 \%$ \\
\hline \multicolumn{7}{|c|}{ Index Only } \\
\hline Adj. R square & 0.902632 & 0.744769 & 0.900920 & 0.955183 & 0.975847 & 0.986345 \\
\hline Alpha & -0.000012 & -0.001773 & -0.001190 & -0.000001 & 0.000919 & 0.002078 \\
\hline T-stats & -0.125239 & -1.973508 & -1.04369 & -0.001036 & 0.850925 & 1.522797 \\
\hline$\sigma_{\alpha}=0.00182$ & \multicolumn{6}{|c|}{$\%$ of positive (negative) alphas with p-values $\leq 0.05: 6.16 \%(10.27 \%)$} \\
\hline \multicolumn{7}{|c|}{ Index + Homebuilders } \\
\hline Adj. R square & 0.914594 & 0.773031 & 0.905767 & 0.957033 & 0.976330 & 0.986124 \\
\hline Alpha & -0.000741 & -0.002579 & -0.001576 & -0.000508 & 0.000337 & 0.001025 \\
\hline T-stats & -0.571429 & -2.16294 & -1.524305 & -0.525014 & 0.32862 & 1.134693 \\
\hline$\sigma_{\alpha}=0.00196$ & \multicolumn{6}{|c|}{$\%$ of positive (negative) alphas with p-values $\leq 0.05: 3.42 \%(14.38 \%)$} \\
\hline \multicolumn{7}{|c|}{ Index + Characteristic Factors } \\
\hline Adj. R square & 0.920252 & 0.806786 & 0.91975 & 0.955494 & 0.976908 & 0.987345 \\
\hline Alpha & -0.000528 & -0.002427 & -0.001491 & -0.000309 & 0.000568 & 0.001314 \\
\hline T-stats & -0.42964 & -2.134062 & -1.298892 & -0.291524 & 0.516231 & 1.261552 \\
\hline$\sigma_{\alpha}=0.00178$ & \multicolumn{6}{|c|}{$\%$ of positive (negative) alphas with p-values $\leq 0.05: 5.48 \%(12.33 \%)$} \\
\hline \multicolumn{7}{|c|}{ Index + Characteristic Factors + Homebuilders } \\
\hline Adj. R square & 0.928 & 0.824374 & 0.919428 & 0.957491 & 0.976515 & 0.987266 \\
\hline Alpha & -0.001063 & -0.002985 & -0.001805 & -0.000795 & 0.000224 & 0.000973 \\
\hline T-stats & -0.771834 & -2.898379 & -1.683938 & -0.783021 & 0.239817 & 1.059186 \\
\hline$\sigma_{\alpha}=0.00218$ & \multicolumn{6}{|c|}{$\%$ of positive (negative) alphas with p-values $\leq 0.05: 3.42 \%(18.49 \%)$} \\
\hline \multicolumn{7}{|c|}{ Index + Property Type Factors } \\
\hline Adj. R square & 0.918186 & 0.774156 & 0.908595 & 0.962672 & 0.978111 & 0.990082 \\
\hline Alpha & -0.000025 & -0.002089 & -0.001245 & 0.000025 & 0.001021 & 0.001956 \\
\hline T-stats & -0.141473 & -2.211532 & -1.167726 & 0.008985 & 0.928812 & 1.787704 \\
\hline$\sigma_{\alpha}=0.00199$ & \multicolumn{6}{|c|}{$\%$ of positive (negative) alphas with p-values $\leq 0.05: 7.53 \%(10.96 \%)$} \\
\hline \multicolumn{7}{|c|}{ Index + Property Type Factors + Homebuilders } \\
\hline Adj. R square & 0.925955 & 0.809424 & 0.908789 & 0.964297 & 0.979656 & 0.989807 \\
\hline Alpha & -0.000464 & -0.002628 & -0.00152 & -0.000424 & 0.000644 & 0.00143 \\
\hline T-stats & -0.419538 & -2.223684 & -1.364358 & -0.397502 & 0.613315 & 1.56445 \\
\hline$\sigma_{\alpha}=0.0019$ & \multicolumn{6}{|c|}{$\%$ of positive (negative) alphas with p-values $\leq 0.05: 4.79 \%(11.64 \%)$} \\
\hline \multicolumn{7}{|c|}{ Index + Statistical Factors } \\
\hline Adj. R square & 0.927135 & 0.831071 & 0.935677 & 0.962484 & 0.980552 & 0.989259 \\
\hline Alpha & -0.000045 & -0.002262 & -0.001231 & -0.000052 & 0.000964 & 0.001960 \\
\hline T-stats & -0.11619 & -1.863425 & -1.207681 & -0.050681 & 0.81108 & 1.641077 \\
\hline$\sigma_{\alpha}=0.00201$ & \multicolumn{6}{|c|}{$\%$ of positive (negative) alphas with p-values $\leq 0.05: 6.85 \%(8.9 \%)$} \\
\hline \multicolumn{7}{|c|}{ Index + Statistical Factors + Homebuilders } \\
\hline Adj. R square & 0.935321 & 0.853144 & 0.935867 & 0.963516 & 0.979787 & 0.989205 \\
\hline Alpha & -0.000836 & -0.002871 & -0.001729 & -0.000698 & 0.000452 & 0.001275 \\
\hline T-stats & -0.558025 & -2.212476 & -1.43896 & -0.653073 & 0.406727 & 1.243441 \\
\hline$\sigma_{\alpha}=0.0021$ & \multicolumn{6}{|c|}{$\%$ of positive (negative) alphas with p-values $\leq 0.05: 3.42 \%(13.01 \%)$} \\
\hline
\end{tabular}

Number of funds: 146. 
Table 8: Adjusted R squares, Alphas and T-statistics of Alphas for REIT Mutual Funds, Before Fees.

This table presents means, 10th percentiles, 25th percentiles, medians, 75th percentiles, and 90th percentiles of the distributions of adjusted $\mathrm{R}$ squares, alphas, and t-statistics of alphas, for excess returns to individual REIT mutual funds with respect to a variety of explanatory variables, as well as the standard deviation of the alphas, and the percentage of firms that realize alphas that are positive and significant at the $5 \%$ level. The variables consist of the excess returns to the Dow-Jones Wilshire index, a 3 -factor model of the index plus two firm-characteristic factors, namely a book-to-market- and a size factor computed using only REITs, a 6 -factor model of the index and six property-type portfolios, and a 14-factor model of the index augmented by the 13 statistical factors from the triple-sorted portfolios presented in table 3. Each model in turn is also augmented by the index of homebuilders. For our sample of funds, we combine funds within the same family which seem to hold the same portfolio. All returns are before expenses.

\begin{tabular}{|c|c|c|c|c|c|c|}
\hline Figure & Mean & $10 \%$ & $25 \%$ & Median & $75 \%$ & $90 \%$ \\
\hline \multicolumn{7}{|c|}{ Index Only } \\
\hline Adj. R square & 0.899541 & 0.702734 & 0.886946 & 0.954243 & 0.975152 & 0.98628 \\
\hline Alpha & 0.001354 & -0.000631 & 0.000262 & 0.001457 & 0.002043 & 0.003289 \\
\hline T-stats & 1.186317 & -0.685829 & 0.29197 & 1.239449 & 2.031819 & 3.03267 \\
\hline$\sigma_{\alpha}=0.00182$ & \multicolumn{6}{|c|}{$\%$ of positive (negative) alphas with p-values $\leq 0.05: 26.43 \%(2.86 \%)$} \\
\hline \multicolumn{7}{|c|}{ Index + Homebuilders } \\
\hline Adj. R square & 0.911972 & 0.740618 & 0.90269 & 0.955361 & 0.975237 & 0.986064 \\
\hline Alpha & 0.00061 & -0.00135 & -0.000125 & 0.0008 & 0.001882 & 0.002468 \\
\hline T-stats & 0.721789 & -1.186913 & -0.103882 & 0.779322 & 1.635013 & 2.669439 \\
\hline$\sigma_{\alpha}=0.00191$ & \multicolumn{6}{|c|}{$\%$ of positive (negative) alphas with p-values $\leq 0.05: 17.86 \%(3.57 \%)$} \\
\hline \multicolumn{7}{|c|}{ Index + Characteristic Factors } \\
\hline Adj. R square & 0.917941 & 0.805778 & 0.898734 & 0.95525 & 0.97609 & 0.988178 \\
\hline Alpha & 0.000828 & -0.00085 & -0.000151 & 0.001015 & 0.001894 & 0.002563 \\
\hline T-stats & 0.893135 & -0.930606 & -0.119224 & 0.972066 & 1.936742 & 2.690789 \\
\hline$\sigma_{\alpha}=0.00171$ & \multicolumn{6}{|c|}{$\%$ of positive (negative) alphas with p-values $\leq 0.05: 24.29 \%(3.57 \%)$} \\
\hline \multicolumn{7}{|c|}{ Index + Characteristic Factors + Homebuilders } \\
\hline Adj. R square & 0.926138 & 0.821072 & 0.909569 & 0.956869 & 0.975842 & 0.987833 \\
\hline Alpha & 0.000281 & -0.001674 & -0.000523 & 0.000612 & 0.001588 & 0.002246 \\
\hline T-stats & 0.528138 & -1.287691 & -0.503316 & 0.511534 & 1.624577 & 2.329724 \\
\hline$\sigma_{\alpha}=0.00211$ & \multicolumn{6}{|c|}{$\%$ of positive (negative) alphas with p-values $\leq 0.05: 19.29 \%(8.57 \%)$} \\
\hline \multicolumn{7}{|c|}{ Index + Property Type Factors } \\
\hline Adj. R square & 0.91565 & 0.734656 & 0.902323 & 0.961733 & 0.97749 & 0.989721 \\
\hline Alpha & 0.001382 & -0.000746 & 0.00014 & 0.001292 & 0.002426 & 0.0031 \\
\hline T-stats & 1.209916 & -0.680398 & 0.126693 & 1.243153 & 2.205727 & 3.42272 \\
\hline$\sigma_{\alpha}=0.00198$ & \multicolumn{6}{|c|}{$\%$ of positive (negative) alphas with p-values $\leq 0.05: 30 \%(2.86 \%)$} \\
\hline \multicolumn{7}{|c|}{ Index + Property Type Factors + Homebuilders } \\
\hline Adj. R square & 0.923758 & 0.787124 & 0.902907 & 0.963152 & 0.977907 & 0.989375 \\
\hline Alpha & 0.000938 & -0.000959 & -0.000209 & 0.000949 & 0.00215 & 0.002626 \\
\hline T-stats & 0.914696 & -0.773503 & -0.246148 & 0.92332 & 1.887791 & 3.19535 \\
\hline$\sigma_{\alpha}=0.00186$ & \multicolumn{6}{|c|}{$\%$ of positive (negative) alphas with p-values $\leq 0.05: 22.14 \%(2.86 \%)$} \\
\hline \multicolumn{7}{|c|}{ Index + Statistical Factors } \\
\hline Adj. R square & 0.924881 & 0.800631 & 0.930724 & 0.958522 & 0.979722 & 0.989585 \\
\hline Alpha & 0.001319 & -0.000739 & 0.000033 & 0.001366 & 0.002302 & 0.003346 \\
\hline T-stats & 1.123287 & -0.78024 & 0.033099 & 1.074476 & 2.208032 & 3.041706 \\
\hline$\sigma_{\alpha}=0.00199$ & \multicolumn{6}{|c|}{$\%$ of positive (negative) alphas with p-values $\leq 0.05: 29.29 \%(2.86 \%)$} \\
\hline \multicolumn{7}{|c|}{ Index + Statistical Factors + Homebuilders } \\
\hline Adj. R square & 0.93346 & 0.840094 & 0.933486 & 0.962462 & 0.979283 & 0.989506 \\
\hline Alpha & 0.000498 & -0.002024 & -0.000422 & 0.000742 & 0.001723 & 0.002297 \\
\hline T-stats & 0.621888 & -1.347694 & -0.30765 & 0.687197 & 1.766595 & 2.362515 \\
\hline$\sigma_{\alpha}=0.00201$ & \multicolumn{6}{|c|}{$\%$ of positive (negative) alphas with p-values $\leq 0.05: 15 \%(3.57 \%)$} \\
\hline
\end{tabular}

Number of funds: 146. 


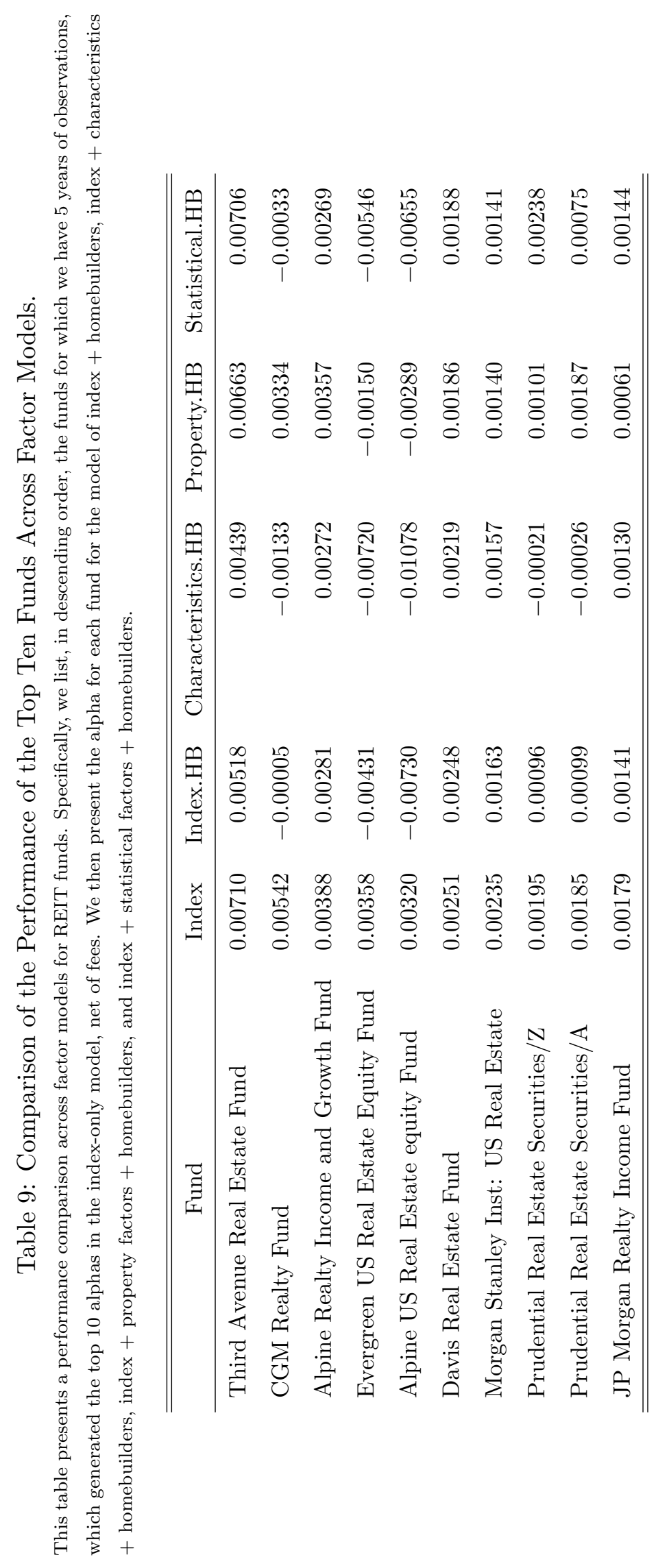




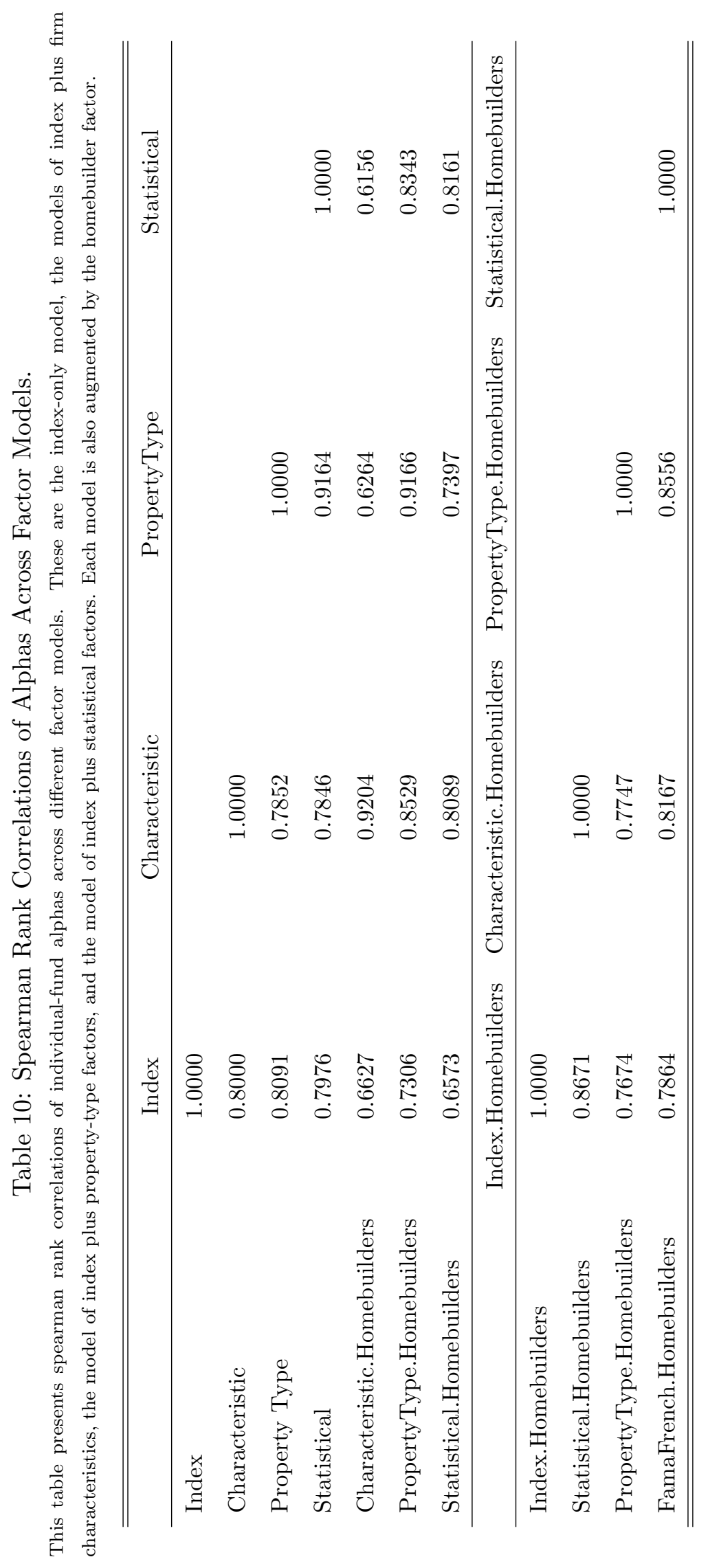


Table 11: Fund Performance as a Function of Fund Characteristics.

This table presents results from Fama-Macbeth (1973) regressions of annual fund returns (before fees) on a constant, the natural logarithm of the fund's total NAV lagged by one year, expense ratio, turnover, number of holdings, and a load indicator which is equal to one if the fund has a nonzero front or rear load and zero otherwise.

\begin{tabular}{lcc}
\hline \hline & Coefficient & t-statistic \\
\hline \multicolumn{3}{c}{ Before Expenses } \\
\hline Intercept & 0.1619 & $2.2765^{\circ}$ \\
Ln$\left._{\text {Size }} t-1\right)$ & 0.0005 & 0.3960 \\
Expenses & -0.5314 & -0.6731 \\
Turnover & 0.0182 & 1.7709 \\
Holdings & -0.0001 & -0.7128 \\
Load & 0.0021 & 0.3049 \\
\hline Average $\overline{R^{2}}$ & 0.0877 \\
\hline \hline
\end{tabular}

${ }^{\circ}: p<10 \% ;^{*}: p<5 \%{ }^{* *}: p<1 \%{ }^{* * *}: p<0.1 \% .8$ time-series observations. 
Figure 1: Box and whisker diagrams of the distrbutions of alphas generated by the single index model, and four different models including Homebuilders. The heavy line in the middle of each box indicates the median, the lower and upper edges indicate the first- and third quartiles respectively, while the whiskers extend 1.5 times the interquartile range outward from the edge of the box. Any outliers that lie beyond this distance are indicated individually by a circle. Index represents the alphas from a model of the Dow Jones Wilshire REIT Index only. Char, Prop, and Stat denote models using the single Index, plus the chracteristic factors, property factors, and statistical factors, respectively. The suffix ".HB" indicates models that include the Homebuilders index.

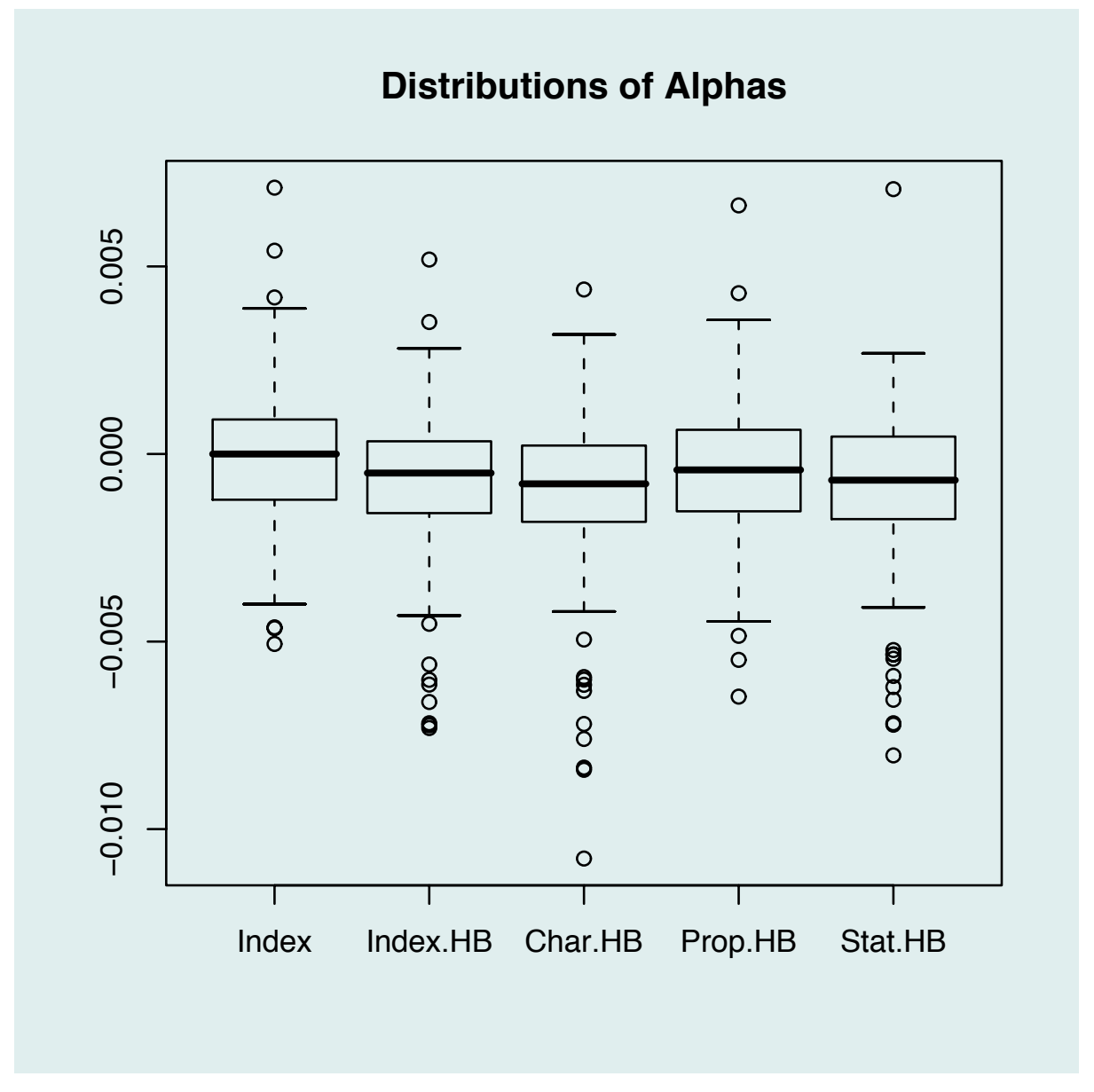

